\title{
Mental Health of Healthcare Personnel during Quarantine for Infectious Epidemic--Real-time Data
}

\author{
Uriel Halbreich ${ }^{1 *}$ and Fanqiang Meng ${ }^{2}$ \\ ${ }^{1}$ Chair, World Psychiatric Association (WPA) Section on Interdisciplinary Collabora- \\ tion and Professor of Psychiatry, Director of Bio-Behavioral Research, Jacob`s School of \\ Medicine and Biomedical Sciences, University at Buffalo, The State University of New- \\ York (SUNY-AB), USA \\ ${ }^{2}$ Professor of Psychiatry, Beijing University, President and CEO, H\&J CRO International, \\ Beijing, China \\ *Corresponding Author: Uriel Halbreich, Chair, World Psychiatric Association (WPA) \\ Section on Interdisciplinary Collaboration and Professor of Psychiatry, Director of Bio- \\ Behavioral Research, Jacob`s School of Medicine and Biomedical Sciences, University at \\ Buffalo, The State University of New-York (SUNY-AB), USA.
}

Received: April 02, 2020

Published: April 28, 2020

(C) All rights are reserved by Uriel Halbreich and Fanqiang Meng.

\begin{abstract}
Background: The 2020 Coronavirus (COVID-19) pandemic has been causing significant fear and anxiety among the general public and demonstrate insufficient preparedness of Healthcare systems. It shed light on front-line Healthcare-personnel who should function and treat others while they share the same stressful situations.

Objective: To provide actual real-time data on mood and mental symptoms of Healthcare personnel in quarantined wards during the Chinese-SARS epidemic, in order to support procedures for functioning of personnel during current and future epidemics. Setting, Participants and Measurements: Cross-sectional Study was conducted during the acute exacerbation of the SARS epidemic at quarantined wards by nurses who were embedded and quarantined with the patients. Mood and perceptions of Healthcare-personnel infected $(n=55)$ and not infected $(n=149)$ with SARS, as well as those during quarantine "rehabilitation" $(n=62)$ were compared to SARS patients $(n=96)$, healthy quarantined students $(n=55)$ and healthy non-quarantined controls $(n=52)$.Structured interviews were conducted with the Beck Depression Inventory (BDI), Spielberger's State-Trait inventory, symptoms Checklist-90 (SCL-90) and a situation-specific questionnaire.

Results: Healthcare-personnel -- infected and not-infected, suffered as much mood, anxiety and other stress-induced symptoms as their SARS patients. Strictly enforced quarantine amplified personnel's frustration, mental symptoms and mistrust in authorities. Limitations: Data was collected when many patients were assisted by respirators, some could not be included.

Conclusion: During acute epidemics front-line Healthcare-Personnel are exposed to same and even more extreme situations as their patients. Their emotional state under tumultuous situations should be of concern.

Implications: Mental well-being procedures and enhancement of Mental resilience of Healthcare teams should be an integral component of their preparedness for future disasters.
\end{abstract}

Keywords: Healthcare Personnel; Corona Virus; SARS; Infectious Diseases; Mental Health; Preparedness; Well-Being

\section{Introduction}

The 2020 coronavirus (COVID-19) pandemic has been a top public concern inducing fear and stress among professionals and populations World-wide, especially in areas in which infected travelers and residents were identified.

The World Health Organization (WHO) immediately convened world experts and funders "to set priorities for COVID-19 research".
A collaborative form of the WHO and Global Research Collaboration for Infectious Diseases Preparedness (GLOPID-R) constructed recommendations [1] which included (at the bottom of the list) "integration of social science in the outbreak response", and "...minimize social and economic impact through multisectoral partnerships". Almost simultaneously it was noted that "Timely mental health care for the 2019 novel Coronavirus outbreak is urgently needed" [2]. The USA Centers for Disease Control and Prevention (CDC) is- 
sued guidelines for actions and preparation which are updated according to cumulative information [3].

Indeed, emphasis during crisis is, and should be on adequate physical life-saving actions and equipment. However, it should be recognized that during any crisis, may it be infectious, natural or man-inflicted, first responders should treat patients and victims while they are under same life-threatening crisis situations. Their emotional state and well-being are of utmost importance for efficacious management of victims. While it is recognized that crises and the considerable uncertainties associated with their impacts and consequences severely affect mental well-being, there is a lack of actual data on mental health collected at real time on-site during the actual crisis. Obviously, such research is not an acute priority when lives are at stack [4].

Here data collected at real-time during the very acute phase of the 2003 SARS epidemic in China [5] is reported. The implications of Public-Health management of that crisis are of importance because during the first 20 years of the $21^{\text {st }}$ century there were several viral epidemics that spread to other countries. Most notable were the 2003 SARS, 2009 N1H1- "Swine Flu", 2012 MERS (Middle East Respiratory Syndrome), 2014 Ebola and now the 2020 Coronavirus (COVID-19). With the enhanced economic and transportation Globalization, Governments and International agencies are preparing (or should be preparing) for next epidemic wave. Data from past occurrences should inform current and future preparedness.

\section{Methods}

\section{Circumstances and environment}

Once the epidemic was recognized, the Chinese authorities in Beijing took extreme measures to curtail it. Patients, suspected patients and contacts were quarantined. Medical personnel from many departments including psychiatry were transferred to Infectious Diseases Hospitals and wards to supplement their staff. Once they arrived, they were also quarantined. Complete isolation of SARS hospitals and facilities was strictly enforced with a new" law of Infectious Diseases" imposed by police and criminal charges. This is in the context of the atmosphere of stress and fear among the general population which may be implied by the flood of treatment-seeking people in Emergency Department reported by the General Hospital to be 5000 per day.

A clinical trial of Major Depressive Disorder conducted at the Institute of Mental Health of Peking University was disrupted and the investigating team were abruptly transferred to Beijing Hospital for Infectious Diseases. They were trained in screening of potential subjects and in the application of structured diagnostic assessments for the clinical trial and gained experience in strict assessments according to research criteria. During the clinical trial the group met regularly and became coherent. Upon arrival at the quarantine ward the nurses noticed that many SARS patients developed mental problems while isolated and called their faculty supervisors in the clinical trial for advice. They suggested to systematically assess their colleagues and patients.

The Dean of the Medical School was contacted and facilitated the investigation. He expedited approval by the Committee for Human Research (the local IRB). The study period in the SARS ward was from May 5 to 12, 2003, less than 3 weeks from the initiation of strict central control measures. Study at the Personnel Rehabilitation facility and students` quarantine was immediately thereafter.

\section{Subjects}

Healthcare personnel infected with SARS: $n=55$, ( 9 males and 46 females, age $31.9 \pm 9.3$ (s.d.) y) who were infected in the hospital while treating their SARS patients, were quarantined at the same ward.

Healthcare personnel working at acute SARS wards (but not infected): 48 doctors ( $29 \mathrm{~m}$ and $19 \mathrm{f}$, age $34.9 \pm 7.8 \mathrm{y}$ ) and 101 nurses (11 $\mathrm{m}$ and $90 \mathrm{f}$, age $29.7 \pm 7.3 \mathrm{y}$ ). Personnel were required to work at the SARS ward for consecutive 6 hours every day. During this time period they could not take off masks, garments, or protective glasses. All their daily routine activities were closely monitored. Following working shifts, they were accommodated, in quarantine, in an adjoining hotel.

Healthcare personnel at rehabilitation quarantined facility: After working in SARS wards for a month, personnel would be transferred to 2-weeks structured, strictly monitored, quarantine "rehabilitation". 62 physicians and nurses (19 m and $43 \mathrm{f}$, age 32.9 $\pm 8.6 \mathrm{y}$ ) participated.

University students isolated for quarantine: When a SARS case was identified in a building or in a class, all residents and all classmates were isolated for 2 weeks for quarantine. Meals and other personal supplies were provided by trained personnel. Strict disinfectant measures were applied. The group of university students at quarantine ( $\mathrm{n}=55,9 \mathrm{~m}$ and $46 \mathrm{f}$, age $28.3 \pm 7.6 \mathrm{y})$ had been isolated for 11 days at the time of the investigation.

Patients with SARS: 96 patients $(29 \mathrm{~m}$ and $67 \mathrm{f}$, age $=34.6+11.4$ years) who were strictly isolated at Beijing Ditan Hospital for Infectious Diseases.

Healthy controls: $(n=52,36 \mathrm{~m}$ and $16 \mathrm{f}$, age $28.0 \pm 6.0 \mathrm{y})$ were physically and mentally healthy volunteers from the community and the Medical University campus who were not hospitalized and at the time of screening did not have any contact with SARS suspected patients. They were assessed as part of the clinical trial. Two psychiatrists (Meng Fanqiang and Liu Jian-cheng) conducted semi- 
structured psychiatric interviews (according to DSM IV criteria) for each volunteer. Volunteers who had a family history, current or lifetime history of any axis I mental disorder as well as current physical and neurological disorders, were excluded.

\section{Assessment instruments}

Self-report questionnaires were used. Patients were assisted by nurses; their responses were verbal and dictated to the nurses.

Beck Depression Inventory (BDI) was previously validated in Chinese [6]. According to previous Chinese norms BDI total score of 0 - 4 is considered as no depression, 5 - 13: moderate depression, 14 - 20: moderately severe depression, and 21 or higher indicates very severe depression.

Chinese validated version of Spielberger's State and Trait Anxiety Inventories (STAI) [7] was applied for assessment of anxiety. The Chinese version of the SCL-90 was applied for more generalized mental symptoms [8]. The SCL-90 provides a total score as well as mean scores of several mental factors including distress level, somatization, depression, anxiety, hostility and interpersonal sensitivity.

Following initial impression of the quarantined nurses` research team as well as telephone interviews with SARS patients, their concerns were formulated to a structured self-report of 14 questions related to information on the disease, confidence in authorities, feelings towards family and caretakers, feeling of being overwhelmed, stress, depression, worries and guilt as well as denial. Severity of items was scored from 1-no, to 4-extremely so.

\section{Statistical analyses}

SPSS statistical package was used for data analysis. For demographic data, frequency analysis was used. Since BDI data had abnormal distribution, Mann-Whitney U and Kruskal Wallis analysis was performed. The STAI groups were compared to each other by student tests.

\section{Results}

Participation rates in the study: Participation rate of personnel in the SARS wards was $84.2 \%$. Quarantined students on campus and controls' acceptance were $77.5 \%$ and $76.3 \%$ respectively. Many patients were on respirators and nurses did not take notes of how many patients refused or were unapproachable because of difficult breathing or any other reasons.

The Ad-hoc questionnaire for the SARS quarantined workers: Table 1 demonstrates that SARS personnel were mostly concerned with the infectious nature of the disease. Of interest is the lack of confidence in the authorities. Subjects reported they were worried or extremely worried that they have infected their family or might be infectious to medical professionals who were taking care

\begin{tabular}{|l|c|c|c|c|}
\hline & No & A little & Yes & Extremely \\
\hline $\begin{array}{l}\text { I have confidence over con- } \\
\text { trolling SARS nationwide }\end{array}$ & 81.3 & 17.7 & 1.0 & 0.0 \\
\hline I know a little about SARS & 26.0 & 55.2 & 14.6 & 4.2 \\
\hline SARS is terrible & 29.2 & 64.6 & 6.3 & \\
\hline I feel lonely and helpless & 71.9 & 21.9 & 6.3 & \\
\hline $\begin{array}{l}\text { I feel being thrown away by } \\
\text { family }\end{array}$ & 95.8 & 3.1 & & 20.8 \\
\hline $\begin{array}{l}\text { I have a lot more words to } \\
\text { say to my family }\end{array}$ & 20.8 & 38.5 & 18.8 & 22.9 \\
\hline $\begin{array}{l}\text { I am dependent on doctors } \\
\text { and nurses }\end{array}$ & 2.1 & 27.1 & 45.8 & 22.9 \\
\hline I miss my family very much & 9.4 & 53.1 & 15.6 & 20.8 \\
\hline $\begin{array}{l}\text { I am worried that I have } \\
\text { infected my family }\end{array}$ & 16.7 & 14.6 & 24.0 & 43.8 \\
\hline $\begin{array}{l}\text { I am worried that I might be } \\
\text { infectious to medical profes- } \\
\text { sionals who are taking care } \\
\text { of me }\end{array}$ & 8.3 & 22.9 & 24.0 & 41.7 \\
\hline $\begin{array}{l}\text { I am being looked down on } \\
\text { by others for having SARS }\end{array}$ & 49.0 & 30.2 & 10.4 & 10.4 \\
\hline $\begin{array}{l}\text { I don't know what to do after } \\
\text { contracting SARS }\end{array}$ & 63.5 & 28.1 & 4.2 & 3.1 \\
\hline $\begin{array}{l}\text { I don't believe I have con- } \\
\text { tracted SARS }\end{array}$ & 64.6 & 30.2 & 2.1 & 1.0 \\
\hline $\begin{array}{l}\text { I feel guilty that I did not } \\
\text { prevent myself from SARS }\end{array}$ & 34.4 & 37.5 & 9.4 & 10.4 \\
\hline
\end{tabular}

Table 1: Ad-hoc questionnaire for the SARS quarantined workers (\%).

of them. Subjects felt highly dependent on doctors. They felt lonely in the ward and missed their family.

The BDI results: Table 2 demonstrates that one-fifth of the patients reported severe depression. The rate was not much lower in their treating personnel. Even when personnel were relieved for rehabilitation (that was still quarantined and highly structured), only less than half did not report any depressive symptoms while $13 \%$ were still clinically depressed. Rate of depression and its severity was highest among quarantined students. It is of note that none of the controls reported any depression and almost no depressive symptoms (they were all a-priori screened to exclude any DSM disorders).

Total scores of the SCL-90: As well as number of positive answers and scores on all factors were significantly higher in all subject groups as compared to controls (Table 3). Both patients and their Healthcare therapists reported similar disturbances. Isolated students had the highest scores. Brief controlled rehabilitation did not improve scores of medical personnel. 


\begin{tabular}{|l|c|c|c|c|}
\hline \multicolumn{1}{|c|}{ Group (n) } & $\begin{array}{c}\text { Moderately severe to very } \\
\text { severe depression (\%) }\end{array}$ & $\begin{array}{c}\text { Moderate } \\
\text { depression (\%) }\end{array}$ & $\begin{array}{c}\text { No depression } \\
\text { (\%) }\end{array}$ & $\begin{array}{c}\text { BDI total score } \\
\text { (mean } \pm \text { SD) }\end{array}$ \\
\hline Medical Personnel & & & & \\
\hline Physicians in SARS ward (48) & 14.6 & 43.7 & 41.7 & $6.77 \pm 5.50^{* *}$ \\
\hline Nurses in SARS WARD (101) & 16.9 & 35.6 & 47.5 & $6.60 \pm 6.45^{* *}$ \\
\hline Medical Workers with SARS (55) & 20.0 & 36.4 & 43.6 & $7.69 \pm 7.34^{* *}$ \\
\hline Physicians and nurses at "rehabilitation" (62) & 12.9 & 40.3 & 46.8 & $6.39 \pm 6.27^{* *}$ \\
\hline Comparison Groups & & & & \\
\hline SARS inpatients (96) & 19.8 & 42.7 & 37.5 & $8.31 \pm 8.08^{* *}$ \\
\hline quarantined students at university campus (55) & 20.9 & 40.4 & 38.7 & $8.23 \pm 7.22^{* *}$ \\
\hline Non-institutionalized, healthy controls (52) & 0.0 & 0.0 & 100.0 & $1.42 \pm 1.58$ \\
\hline
\end{tabular}

Table 2: Beck Depression Inventory (BDI) in SARS Medical personnel and their patients.

Mann-Whitney test, vs Non-institutionalized control group: ${ }^{* *} \mathrm{p}<0.01$.

\begin{tabular}{|l|c|c|c|c|c|c|c|}
\hline \multirow{2}{*}{ Items } & \multicolumn{4}{|c|}{ Medical Personnel } & \multicolumn{3}{c|}{ Comparison Groups } \\
\cline { 2 - 7 } & $\begin{array}{c}\text { Physicians in } \\
\text { SARS ward }\end{array}$ & $\begin{array}{c}\text { Nurses in } \\
\text { SARS ward }\end{array}$ & $\begin{array}{c}\text { Medical work- } \\
\text { ers with SARS }\end{array}$ & $\begin{array}{c}\text { Physicians and } \\
\text { nurses at } \\
\text { rehabilitation }\end{array}$ & $\begin{array}{c}\text { SARS } \\
\text { inpatients }\end{array}$ & $\begin{array}{c}\text { Isolated students } \\
\text { at University } \\
\text { campus }\end{array}$ & $\begin{array}{c}\text { Healthy } \\
\text { controls }\end{array}$ \\
\hline SCL Total & $24.87 \pm 19.34^{* *}$ & $30.22 \pm 31.43^{* *}$ & $37.57 \pm 44.38^{* *}$ & $27.87 \pm 31.66^{* *}$ & $37.72 \pm 41.42^{* *}$ & $50.90 \pm 52.85^{* *}$ & $10.92 \pm 14.65$ \\
\hline $\begin{array}{l}\text { No. of positive } \\
\text { items }\end{array}$ & $21.00 \pm 15.9^{* *}$ & $22.34 \pm 19.18^{* *}$ & $26.51 \pm 21.57^{* *}$ & $21.19 \pm 20.71^{* *}$ & $25.92 \pm 19.85^{* *}$ & $32.89 \pm 28.41^{* *}$ & $9.88 \pm 13.24$ \\
\hline $\begin{array}{l}\text { Somatization } \\
\text { factors }\end{array}$ & $0.28 \pm 0.29^{* *}$ & $0.37 \pm 0.45^{* *}$ & $0.60 \pm 0.57^{* *}$ & $0.37 \pm 0.48^{* *}$ & $0.60 \pm 0.55^{* *}$ & $0.41 \pm 0.45^{* *}$ & $0.10 \pm 0.14$ \\
\hline $\begin{array}{l}\text { Interpersonal } \\
\text { sensitivity }\end{array}$ & $0.34 \pm 0.36^{* *}$ & $0.35 \pm 0.39^{* *}$ & $0.36 \pm 0.52^{*}$ & $0.37 \pm 0.42^{* *}$ & $0.37 \pm 0.51^{* *}$ & $0.70 \pm 0.75^{* *}$ & $0.17 \pm 0.28$ \\
\hline Depression & $0.29 \pm 0.26^{* *}$ & $0.32 \pm 0.41^{* *}$ & $0.39 \pm 0.49^{* *}$ & $0.29 \pm 0.40^{* *}$ & $0.42 \pm 0.53^{* *}$ & $0.59 \pm 0.63^{* *}$ & $0.11 \pm 0.22$ \\
\hline Anxiety & $0.26 \pm 0.26^{* *}$ & $0.36 \pm 0.42^{* *}$ & $0.44 \pm 0.60^{* *}$ & $0.30 \pm 0.36^{* *}$ & $0.43 \pm 0.56^{* *}$ & $0.55 \pm 0.63^{* *}$ & $0.10 \pm 0.18$ \\
\hline Hostility & $0.20 \pm 0.25^{* *}$ & $0.27 \pm 0.42^{* *}$ & $0.36 \pm 0.59^{* *}$ & $0.29 \pm 0.43^{* *}$ & $0.32 \pm 0.52^{* *}$ & $0.62 \pm 0.78^{* *}$ & $0.14 \pm 0.36$ \\
\hline
\end{tabular}

Table 3: SCL-90 scores in medical personnel.

Mann-Whitney test, vs Non-institutionalized control group: ${ }^{*} \mathrm{p}<0.05,{ }^{* *} \mathrm{p}<0.01$.

The Spielberger state and trait anxiety inventory: (STAI) did not reveal any significant difference of subjects' groups (39.2 \pm 4.5 $-42.6 \pm 6.4$ ) as compared to controls (state: $41.3 \pm 10.4$; trait: 40.9 \pm 10.9 ).

\section{Discussion}

We had a unique opportunity to study Mental Well-Being and concerns of quarantined Healthcare providers and their patients by an embedded local team on-site and at real time during the acute initial spread of a highly contagious viral epidemic.

Most current discussions and recommendations are based on retrospective recollections and post-hoc impressions or outside inquiries [9-14]. The real-time on-site data reported here further illuminate and emphasize the need to learn from past experience and consider the Mental well-being of Healthcare personnel and the emotional impact of quarantine as important components of immediate actions and future planning.
Retrospectively it is apparent that during the initial evolving acute spreading stage of the potentially deadly SARS epidemic, Public Health and government authorities were slow in recognizing the gravity of the threat and in providing accurate information and practical advice to professionals and the Public. Medical personnel who treated infected but still inaccurately diagnosed patients were vulnerable to contract the disease and become patients themselves. As is demonstrated by the COVID-19 pandemic, early recognition of potentially-fulminant epidemic is still problematic. Adequately-aggressive response and containment are subject to political connotations. Persuasion of governments at all levels is beyond the scope of the current report, however side-by-side data of past and current Chinese outbreaks should be illuminating to politicians.

Physical and mental status of Healthcare personnel was similar to their patients. Furthermore, it is demonstrated here that depression, anxiety and other mental symptoms of the "healers" 
who were not infected were as prevalent and as severe as those of their patients. Harsh restrictions were imposed on the health providers, "To be on the safe side" and "for their own protection" they were treated as "potentially dangerous patients". Even though the authorities recognized that personnel needed respite from intensive work, personnel in "rehabilitation" were still under strict quarantine and their mental symptoms did not improve. This may suggest that benefits of flexible management of personnel should be weighed versus probable increased risk.

The provision of medical help during acute crisis, when the dangerous situation is still in effect and is unfolding, imposes demands on the professionals who are under the same distressful situation but are required to help their fellows. It should be emphasized that these situations are not limited to infectious epidemics nor to far-away locations. This is demonstrated by the report of a family physician in Missouri, USA immediately following a tornado disaster. He described his own feelings as "confusion, despair, disbelief and disorientation..., they just lost it...it was like being shellshocked... It's hard to maintain one's emotional composure in that setting" [15]. This subjective account of a still-shaken professional underscores the vulnerability and personal involvement of indigenous Healthcare personnel on-site. It also underscores that the provision of medical help during the crisis, when the dangerous situation is still in effect and is unfolding, may be overwhelming to the distressed professionals in-situ if they are not adequately prepared to manage it.

Mental preparedness of Medical personnel for still-unpredictable disastrous situations is challenging. Epidemic infections are prevalent. The question here in not only "where", with Globalization of transportation and travel the question is "how to prepare anywhere". Common denominators among diversified types of crises should be apparent. Natural disasters like floods, earthquakes, volcano eruptions, tsunamis, tornadoes and wildfires are frequent occurrences in vulnerable developing and developed regions. In many areas the question is not "if' rather it is "when". Even the distinction between un-avoidable natural disasters and Man-Inflicted disasters is not that clear. As was demonstrated by the 2011 tsunami-related nuclear accident in Japan, natural forces may be amplified by man-made actions or mis-actions and vice versa. With all these crises exact timing is unpredictable, but their feasibility is quite high. Therefore, Medical response teams should be identified, designated and well-prepared-physically and mentally.

Operational suggestions for future teams' training and preparedness may be drown from our non-intentional situation. We had trained and had a functional clinical- research team in place for another on-going study. They became embedded in the quarantine ward by an emergency Government order.
The team's attitude and skills, their tribulations, complaints and symptoms as well as resilience, initiatives and improvisation under acute stress demonstrate important optimal attributes of the indigenous crisis-intervention team that should be implemented in other emergency situations. Physicians and nurses were all members of the local community and were fully immersed in the local culture. The local coordinator and the team knew each other well and developed a group-spirit. They were proficient in physical exams, physical interventions and structured Psychiatric interviews and were comfortable with meticulous procedures, close monitoring and accurate reporting. They had the administrative and moral support of the hospital and academic hierarchies. Communication channels were maintained by phone despite difficulties. The team were embedded and well-intertwined with the management and general medical groups with whom they shared same institutional cultural attitudes and same experiences. When they were requested to collect data, they responded enthusiastically and saw it as a challenge that needed to be solved, the investigation was in addition to the required clinical duties.

Our team's experience and data suggest that maintaining constant sustainable communication with the outside professional familiar environment and own family are of utmost importance. Lack of and inconsistent information is demoralizing as are regulations that are not sufficiently explained and justified. The quarantine experience across all groups suggests that risk and benefit of quarantine of treatment teams should be evaluated based on data and facts and be flexible according to changing circumstances.

The un-intentional experience of our team suggests that training for pre-determined functions allowed for efficient performance under stress. This data may be interpreted as resilience of the investigating team vis-à-vis the rest of the treating Healthcare personnel of which they were members.

High feasibility of future occurrences coupled with unpredictable timing require every response team to be resilient, flexible and well-prepared. A-priory resilience may be enhanced on two levels. Team members should be screened by culturally sensitive procedures. For future implementations available questionnaires (i.e. Connor-Davidson resilience Scale-CD-RISC) [16] may be adapted and expanded. As would be the case for any team of first responders, mental and physical health responders should be screened and identified as having high resilience to stress, non-vulnerability to mental symptoms, ability to adapt and improvise under stress as well as stamina. Selection procedures for such personality traits are applied in several military units in several countries and may be adjusted to civilian situations.

Following selection, resilience should be amplified, boosted and maintained by repeated practice. It is apparent that in most in- 
stances response and treatment teams would be Primary Care Providers, Emergency and/or Infectious Diseases experts. Therefor screening, enhanced resilience and awareness of possible mood and behavior effects of stress should be part of preparedness of these teams as a preventative measure prior to the emergencies.

Guidelines for mental well-being of treatment teams during emergencies have been recently suggested [17]. Methods to enhance resilience have been previously suggested [18]. It is undisputed that well-being of providers is essential for efficacious care, it should also be established that their well-being under stress depends on their resilience and this should be enhanced prior to next disaster.

The preventative pre-stressors mental preparedness should be better conducted by clinicians who can share with trainees their own experiences. Preferably these should be local or hospitalbased Internists or PCPs. Psychiatrists and other mental health professionals should be available during the preparedness and crisis but should only be in an advisory role. Emphasis is on positive adaptation and utilization of strengths and not on any anticipation of perceived trauma nor anticipation of Post-traumatic Stress disorder (PTSD).

Of utmost importance is the need to apply past data as those which are reported here for future models and practice. This is routinely done by epidemiologists [19], it should be applied for mental well-being and planning during extreme conditions.

\section{Conclusion}

Focus on mental well-being of Healthcare providers is of utmost importance for their functioning under stress and for efficacious care of their patients.

Considering at least 5 wide-spread epidemics during the recent 20 years it is reasonable to predict that more such potentially disastrous occurrences will happen in the near future. Therefore: It is suggested that in addition to the current guidelines for procedures for mental health response following disastrous events [17]. Well-being clinical procedures should be developed and implemented for pre-stressor preparedness. Procedures should not be limited to physical protective gear and protocols.

Resilience abilities should be amplified, and team members should be familiar with any anticipated action as well as be able to improvise if needed.

As part of preventative measures, local teams should be embedded among local populations in areas that are prone to crises. Such teams should be pre-formed and headed by a local Primary Care Provider (PCP) or Internist. Indeed, prospective installment, training and enhancing resilience of embedded teams in vulner- able locations is easier in theory than practice. However, feasibility of initiation and budgeting of operational preparedness in anticipation of next physical disasters are higher when the impact of the current one is fresh.

Resilience preparedness will assure that once the actual crisis or catastrophe occurs, locally adapted action plans should be immediately implemented to maintain team moral, provide them with support and prevent attrition.

It is of note that despite repeated local and Global crises, databased lessons from the past are slow to being accepted. Preventative pre-crisis guidelines and procedures for well-being of Healthcare teams have not been sufficiently implemented yet. Indeed, they should.

\section{Acknowledgment and Disclosures}

The reported data was collected by a research team who were initially trained for a clinical trial sponsored by Eli Lilly Labs. The trial was disrupted by the epidemic. The ad-hoc team was dispersed following the study.

The performance under stress of the Chinese local team is greatly appreciated.

Special thanks are due to Liu Jain-Cheng, Cong Zhong, and Liu Xenhua, who at the time of the study were at the Institute of Mental health of Peking University, Beijing; and Chen Zheng who was at the Dept. of Nursing at Beijing Ditan Hospital for Infectious Diseases. Professor Shen Yucun-- founding director of the Beijing Institute of Mental Health co-established the collaborative projects and diligently facilitated the complex administrative aspects. This report is dedicated to her memory.

The data was presented, in Chinese, at the Annual meeting of the Chinese Psychiatric Association, Shanghai, June 2003 (abstracts: Chinese Ment. Health. J.17*(8,9): 524,526,597).

\section{Financial Support}

The research team was initially trained for a clinical trial sponsored by Eli Lilly Labs. That corporation had no involvement, input nor support of any of other aspects of the study.

\section{Bibliography}

1. World Health Organization (WHO). Strategic preparedness and response plan:2019 Novel Corona virus (2019-nCOV) WHO draft of (2020).

2. Xiang Y-T., et al. "Timely mental health care of the 2019 novel Corona virus outbreak is urgently needed". Lancet Psychiatry (2020). 
3. Centers for Disease Control and Prevention-CDC CDC in action: Preparing Communities for potential spread of COVID-19. Interim US guidance for Risk Assessment and Public Health Management of healthcare Personnel with potential exposure in healthcare setting to patients with Coronavirus disease (COVID-19) (2020).

4. WHO Coronavirus Disease (COVID-19) Outbreak: Rights, roles and responsibilities of health Workers including key considerations for occupational safety and health. WHO, Geneva Switzerland (2020).

5. Xu XY., et al. "The clinical epidemiologic characteristics of patients with severe acute respiratory syndrome (SARS)". Beijing Da Xue Xue Bao 35 (2003): 5-6.

6. Liu P. “Beck Depression Inventory (Chinese version)”. In: Manual of Mental Health Rating Scales. Editions: Wang Xiangdong, Ma Hong; Chinese Journal Mental Health (1999):191- 193.

7. Zheng X., et al. "Validation of Chinese version of Spielberger State-Trait Anxiety Inventory, STAI-Form Y". Chinese Journal Mental Health 7 (1993): 60-62.

8. Wang Z. "Chinese version of Symptom Checklist 90, SCL-90". Shanghai Psychiatry 2.2 (1984): 68-70.

9. Goula P., et al. "General hospital staff worries, perceived sufficiency of information and associated psychological distress during the A/H1N1 influenza Pandemic". BMC Infectious Diseases 10 (2010): 322

10. Maunder RG., et al. "Factors associated with the psychological impact of Severe Acute Respiratory Syndrome on nurses and other hospital workers in Toronto". Psychosomatic Medicine 66.6 (2006): 938-942.

11. Styra R., et al. "Impact on health care workers employed in high-risk areas during the Toronto SARS outbreak". Journal of Psychosomatic Research 64.2 (2006):177-183.

12. Bai Y-M., et al. "Survey of stress reactions among health-care workers involved with the SARS outbreak". Psychiatric Services 55.9 (2014): 1055-1057.

13. Tam CWC., et al. "Severe Acute respiratory Syndrome (SARS) in Hong-Kong in 2003: stress and psychological impact among frontline health care workers". Psychological Medicine 34.7 (2004): 1197-1204.

14. Wong TW., et al. "The psychological impact of severe acute respiratory syndrome outbreak on health care workers in emergency departments and how they cope". European Journal of Emergency Medicine 2.1 (2005): 13-18.
15. Moyer CS. "Doctors confront burst of mental health problems after disasters". AMA News (2011)

16. Connor KM and Davidson JR "Development of a new resilience scale: The Connor-Davidson resilience scale (CD-RISC)". Depression and Anxiety 18.2 (2003): 76-82.

17. Interagency Standing committee-IASA IASA guidelines for Mental Health and Psycho Social Support (MHPSS) in emergency settings (2020).

18. Southwick SM and Charney DS. "Resilience-The science of mastering life `s greatest challenges". Cambridge University Press, New York, London (2012)

19. Pueyo T. Coronavirus: why you must act now-Politicians, Community Leaders and Business Leaders: what you should do and when? (2020).

\section{Assets from publication with us}

- Prompt Acknowledgement after receiving the article

- Thorough Double blinded peer review

- Rapid Publication

- Issue of Publication Certificate

- High visibility of your Published work

Website: $\underline{w w w . a c t a s c i e n t i f i c . c o m / ~}$

Submit Article: www.actascientific.com/submission.php Email us: editor@actascientific.com

Contact us: +919182824667 